\title{
Adherence to Cardio-protective Medications Prescribed for Secondary Prevention after an Acute Coronary Syndrome Hospitalization Compared to Usual Care
}

\author{
Jamal S. Rana, MD, PhD ${ }^{1,2,3}$, Melissa M. Parker, MS ${ }^{3}$, Jennifer Y. Liu, MPH , Howard H. Moffet, MPH', \\ and Andrew J. Karter, $P h D^{3,4,5}$
}

'Division of Cardiology, Kaiser Permanente Northern California, Oakland, CA, USA; ${ }^{2}$ Department of Medicine, University of California, San Francisco, San Francisco, CA, USA; ${ }^{3}$ Division of Research, Kaiser Permanente Northern California, Oakland, CA, USA; ${ }^{4}$ Department of General Internal Medicine, University of California, San Francisco, San Francisco, CA, USA; ${ }^{5}$ Departments of Epidemiology and Health Services, University of Washington, Seattle, WA, USA.

KEY WORDS: medication adherence; secondary prevention; acute coronary syndrome; myocardial infarction.

J Gen Intern Med 33(10): 1621-2

DOI: $10.1007 / \mathrm{s} 11606-018-4519-2$

(c) Society of General Internal Medicine 2018

\section{INTRODUCTION}

Secondary prevention after an acute coronary syndrome (ACS) hospitalization is critical to prevent additional morbidity and mortality. While poor adherence to prescribed cardioprotective medications is a known problem, ${ }^{1,2}$ it is unknown whether an ACS event might motivate patients to achieve better adherence. In a large integrated health care population, we examined initiation and adherence to newly prescribed cardio-protective medications among post-ACS event patients compared to patients who were prescribed these same medications in usual care.

\section{METHODS}

Among adult (age $\geq 40$ years) members of Kaiser Permanente Northern California (KPNC), an integrated health care system, we evaluated adherence to newly prescribed cardio-protective medication classes (beta-blockers, statins, angiotensinconverting enzyme inhibitors/angiotensin receptor blockers [ACE-I/ARB], and platelet P2Y12 receptor inhibitors) after a hospitalization for ACS (exposed group); we compared adherence to the same medication classes prescribed to outpatients in usual care (reference group).

We identified KPNC patients with a first ACS event hospitalization during January 1, 2006, to December 31, 2013 , based on a validated algorithm that uses primary discharge diagnoses of ICD9 codes 410 and $411^{2}$; we identified discharge prescribing orders for the medications of interest and all subsequent dispensing from KPNC pharmacies (KPNC membership covers only dispensing from KPNC pharmacies; use of outside pharmacies is $\operatorname{rare}^{3}$ ).

We compared adherence in a reference group of ambulatory patients who had been newly prescribed any of the same cardio-protective medications in usual care and who had not experienced an ACS event (in the 5 years prior to prescribing date). We used risk-set sampling to match reference prescriptions by medication class and by prescribing year to each prescription in the exposed group to control for secular trends in adherence and to estimate the effect of an ACS event on adherence.

Adherence was estimated using the following definitions based on validated methods. ${ }^{3}$ Primary non-adherent (never filled) was defined as no dispensing of the medication within 60 days of the electronic prescription order. Early nonpersistent (no refills) was defined as primary adherent but no refill within the period defined by the number of days' supply of medication initially dispensed plus a 90-day grace period. Later stage non-persistent (discontinued within 15 months (or 12 months for P2Y12)) was defined as early persistent (i.e., at least one refill), but no refill within 90 days after the end of the total days' supply of previous dispensing.

\section{RESULTS}

The final study population $(N=50,941)$ included 16,068 patients hospitalized for ACS (and their 35,829 new prescriptions) and 34,873 patients in the reference group (and their 35,548 new prescriptions). Primary non-adherence (0.6$1.2 \%$ ) and early non-persistence (5.9-7.8\%) for the four medication classes were low among ACS patients and significantly better than rates in usual care $(3.2-10.4 \%$ and $12.6-30.0 \%$, respectively) $(p<0.0001$ for all) (Fig. 1). While many ACS patients discontinued their medications during follow-up (16.7\% beta blockers; $17.2 \%$ statins; $19.8 \%$ ACE-I/ARB; $15.1 \%$ platelet $\mathrm{P} 2 \mathrm{Y} 12$ receptor inhibitors), rates of discontinuation in usual care were much greater (25.4-52.5\%). 


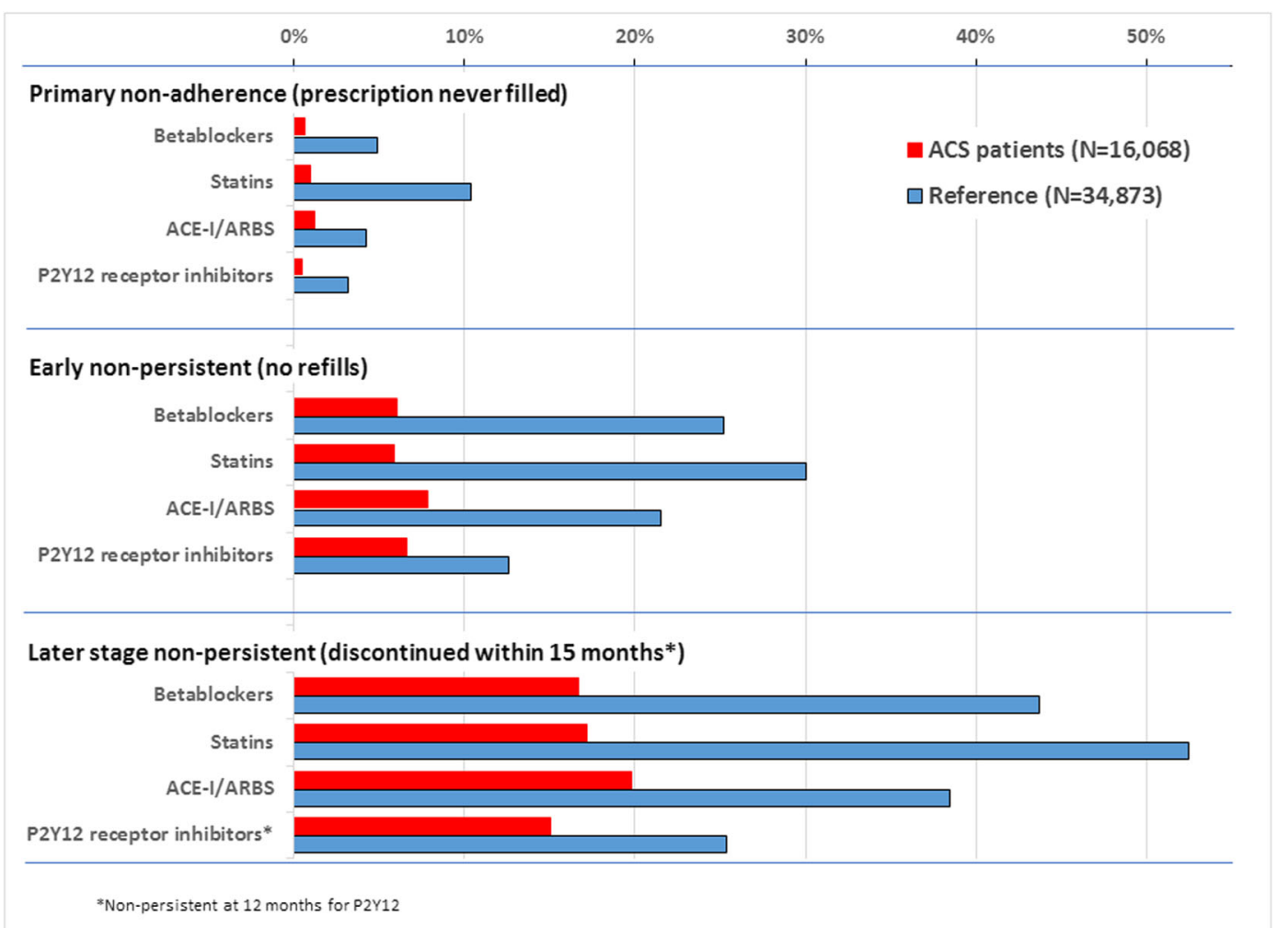

Figure 1 Adherence rates for four major medication classes. ACS patients were statistically more adherent $(p<0.0001)$ than reference group for all medications, in each category of adherence.

\section{DISCUSSION}

Strengths of this study include the large cohort with 12 15 months of follow-up and a robust adherence methodology based on pharmacy dispensing records in this closed health care system. We did not assess adherence to aspirin, an essential medication for this patient population, because it is often obtained over-the-counter and thus not reliably measurable from pharmacy dispensing.

Adherence to newly prescribed cardio-protective medications was excellent among ACS patients discharged from the hospital, and substantially better than patients prescribed the same medications in usual care, suggesting that experiencing an ACS event may motivate patients to be more adherent to medications prescribed at discharge than they might be in usual care. However, despite having had an ACS event, and although better adherence than a similar, previously reported study, ${ }^{4}$ adherence over time among ACS patients remained suboptimal.

Our study in a large real world contemporary population illustrates that post-ACS medication adherence was much better than that observed among patients receiving the same medications in usual care, perhaps due to motivation conferred by the ACS event itself. Nonetheless, medication adherence was suboptimal even in ACS patients, limiting the potential benefits of these proven treatments. Multifactorial interventions that address the various psychosocial, socioeconomic, and behavioral patient barriers are needed to improve adherence in these high-risk patients. ${ }^{5}$
Corresponding Author: Jamal S. Rana, MD, PhD; Division of Cardiology Kaiser Permanente Northern California, Oakland, CA, USA (e-mail: jamal.s.rana@kp.org).

Funding Information This work was supported by Community Benefits grant by Kaiser Permanente Northern California.

\section{Compliance with Ethical Standards:}

Conflict of Interest: The authors declare that they do not have a conflict of interest.

\section{REFERENCES}

1. Bansilal S, Castellano JM, Garrido E, et al. Assessing the Impact of Medication Adherence on Long-Term Cardiovascular Outcomes. J Am Coll Cardiol 2016;68(8):789-801.

2. Varas-Lorenzo C, Castellsague J, Stang MR, Tomas L, Aguado J, PerezGutthann S. Positive predictive value of ICD-9 codes 410 and 411 in the identification of cases of acute coronary syndromes in the Saskatchewan Hospital automated database. Pharmacoepidemiol Drug Saf 2008; 17(8):842-852

3. Parker MM, Moffet HH, Adams A, Karter AJ. An algorithm to identify medication nonpersistence using electronic pharmacy databases. J Am Med Inform Assoc 2015;22(5):957-961.

4. Choudhry NK, Avorn J, Glynn RJ, et al. Full coverage for preventive medications after myocardial infarction. N Engl J Med 2011;365(22):20882097.

5. Hirsh BJ, Smilowitz NR, Rosenson RS, Fuster V, Sperling LS. Utilization of and Adherence to Guideline-Recommended Lipid-Lowering Therapy After Acute Coronary Syndrome: Opportunities for Improvement. J Am Coll Cardiol 2015;66(2):184-192. 